\title{
Conceptual approach to lateral salinity gradients around roots of salt-sensitive and salt-tolerant crops under irrigation conditions
}

\author{
Uwe Schleiff \\ Independent Expert for Salinity \& Irrigation, Fertilizers \& Crops, Soils \& Environment, \\ D-38300 Wolfenbuettel, P.O. Box 1934, Germany \\ e-mail: schleiff@salinity.de
}

\begin{abstract}
Summary. Under controlled crop irrigation with brackish water, a vertical soil salinity gradient develops in the rooted soil layer. Furthermore, in periods of soil water depletion, due to ion exclusion by roots, a transpiration-driven, lateral build-up of a salinity gradient between the soil fraction adjacent to roots and distant, occurs. Root morphological traits determine the volume of the soil fraction, in which salt accumulation occurs (rhizospheric soil volume). The increase of soil salinity near roots is greater, when plant roots form a small rhizospheric soil volume (e.g. leek). When roots form a larger rhizospheric soil volume, salts are distributed throughout a larger soil volume, which improves conditions for root water uptake and crop salt tolerance (e.g. rape).
\end{abstract}

Key words: crop salt tolerance, brackish irrigation, soil/root-interface, root morphology.

\section{Introduction}

In the dry areas of the world, irrigated crop production and landscape greening replace good quality irrigation waters, by brackish waters, e.g. groundwater or treated sewage water. Consequently, there is also an increasing need for plants that can flourish in salt affected soils. Earlier concepts of crop salt tolerance rating for brackish water irrigation are soil-based and concentrate only on vertical salinity distribution in the rooted soil layer. In Figure 1, salinity distribution under controlled management of brackish water results from varying rooting densities, which depend upon the type of crop and the irrigation method. However, this classical concept does not acknowledge the transpiration driven lateral salinity gradient between the soil fraction adjacent to the root surface (rhizospheric soil) and the soil distant from root surface (bulk soil) forming between water applications. My focus shall be on this aspect.

\section{Conceptual approach}

Under brackish irrigation plant water supply occurs from saline soil water. During periods of soil water depletion, by roots, most salts are excluded from root uptake. Consequently, accumulation of easily water soluble salts occurs in the soil fraction contacting roots and a lateral soil salinity gradient between soil adjacent to and distant from the roots builds up (Riley \& Barber 1970). As indicated in Figure 2, I expect root traits to significantly affect the build-up of salinity gradients. When plants are equipped with a root system, forming a relatively small rhizo-spheric soil volume (per unit root dry matter), the increase in rhizospheric soil water salinity (per unit absorbed soil water) will be greater, when compared to roots that form a larger rhizospheric soil volume. Therefore, this factor affects crop salt tolerance (Schleiff 1987, 2010). 


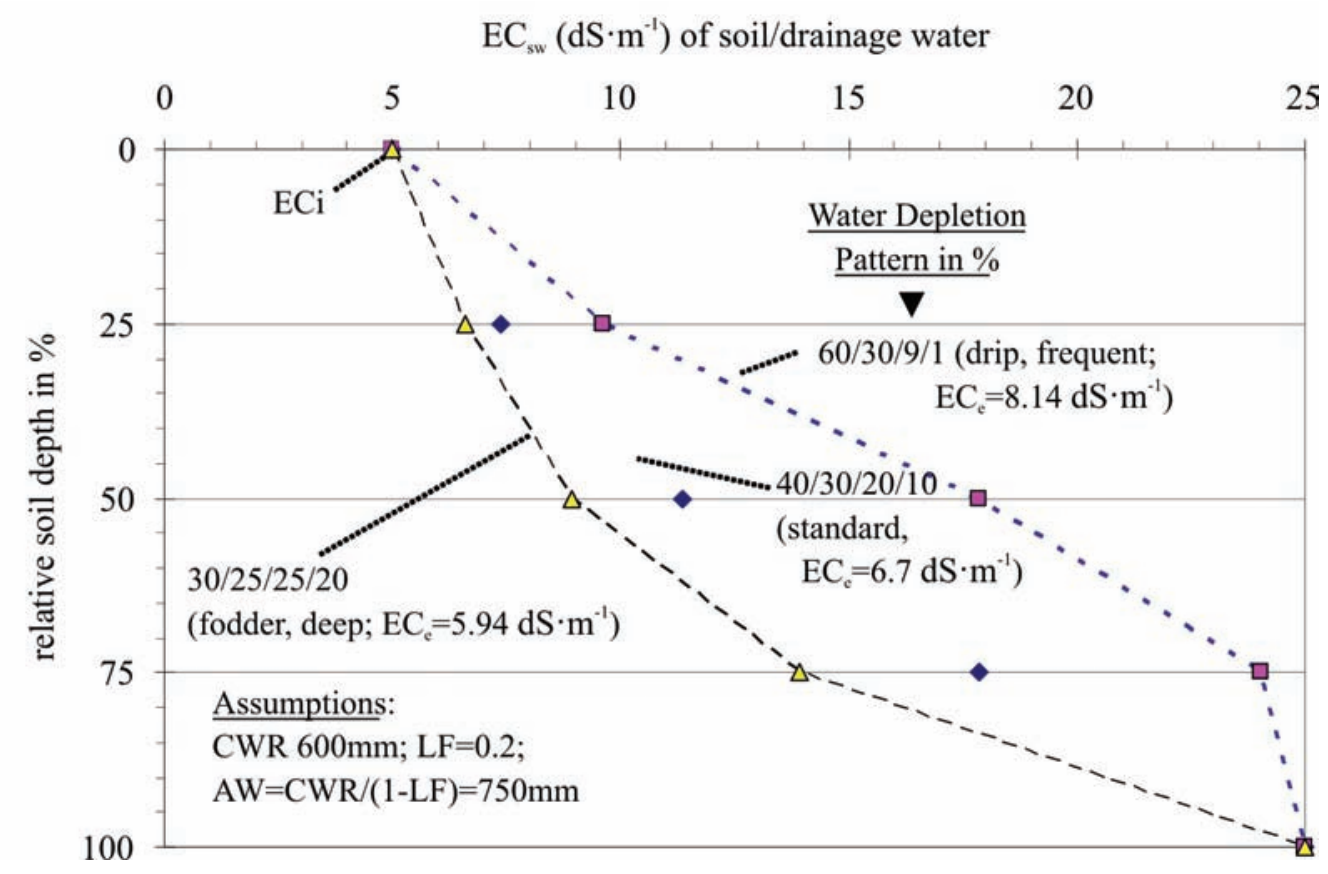

Figure 1. Vertical soil salinity profiles under brackish irrigation $\left(\mathrm{EC}_{\mathrm{i}}=5 \mathrm{dS} \cdot \mathrm{m}^{-1}\right)$ as calculated for a standard crop, a deep rooting crop, and under frequent (drip) irrigation

\section{$\underline{\text { IMPAIRMENT }}$ EFFECT ON SALT TOLERANCE $\backslash$ IMPROVEMENT}

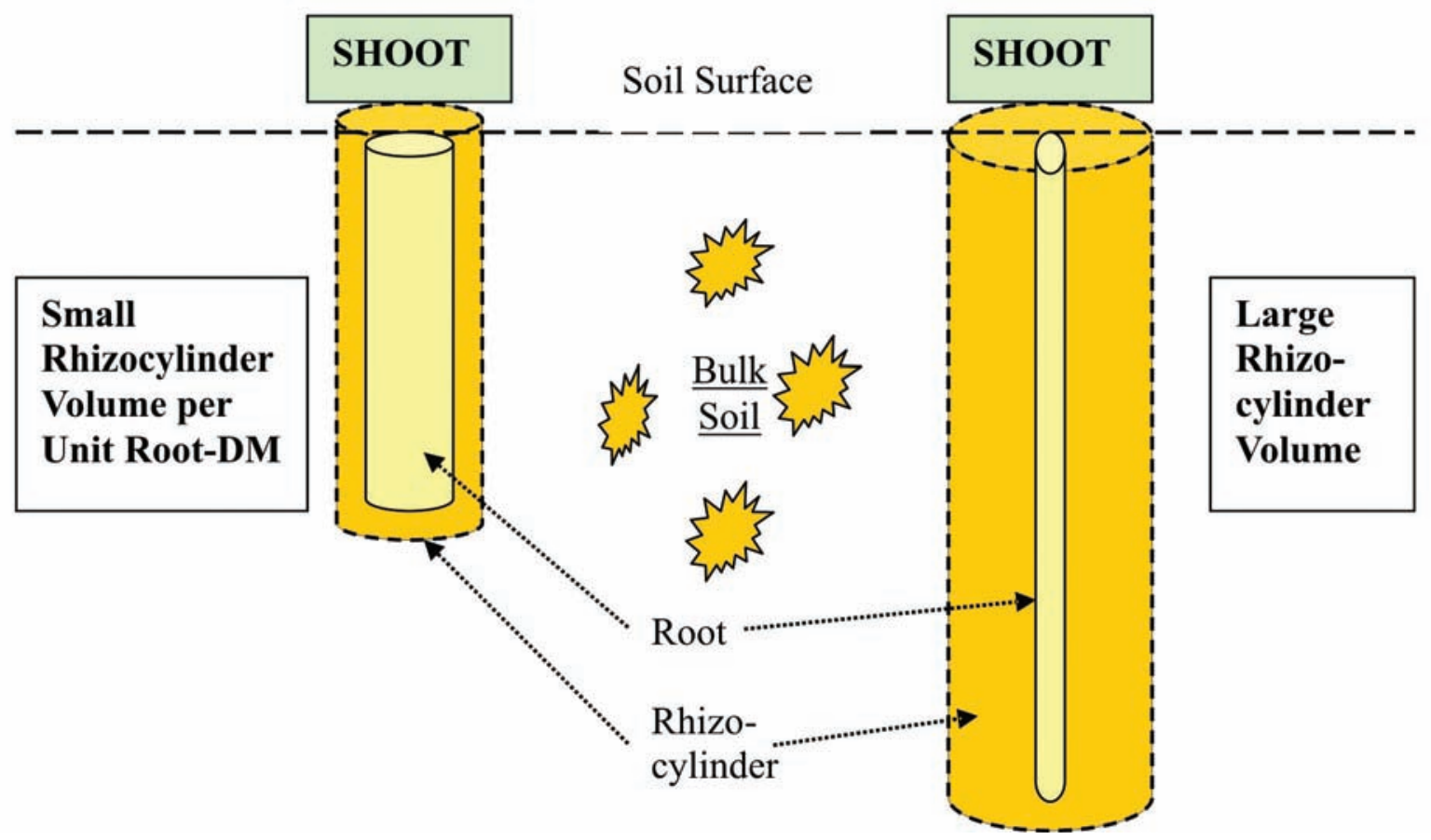

Figure 2. Crop salt tolerance as affected by root morphology and volume of rhizocylinder 


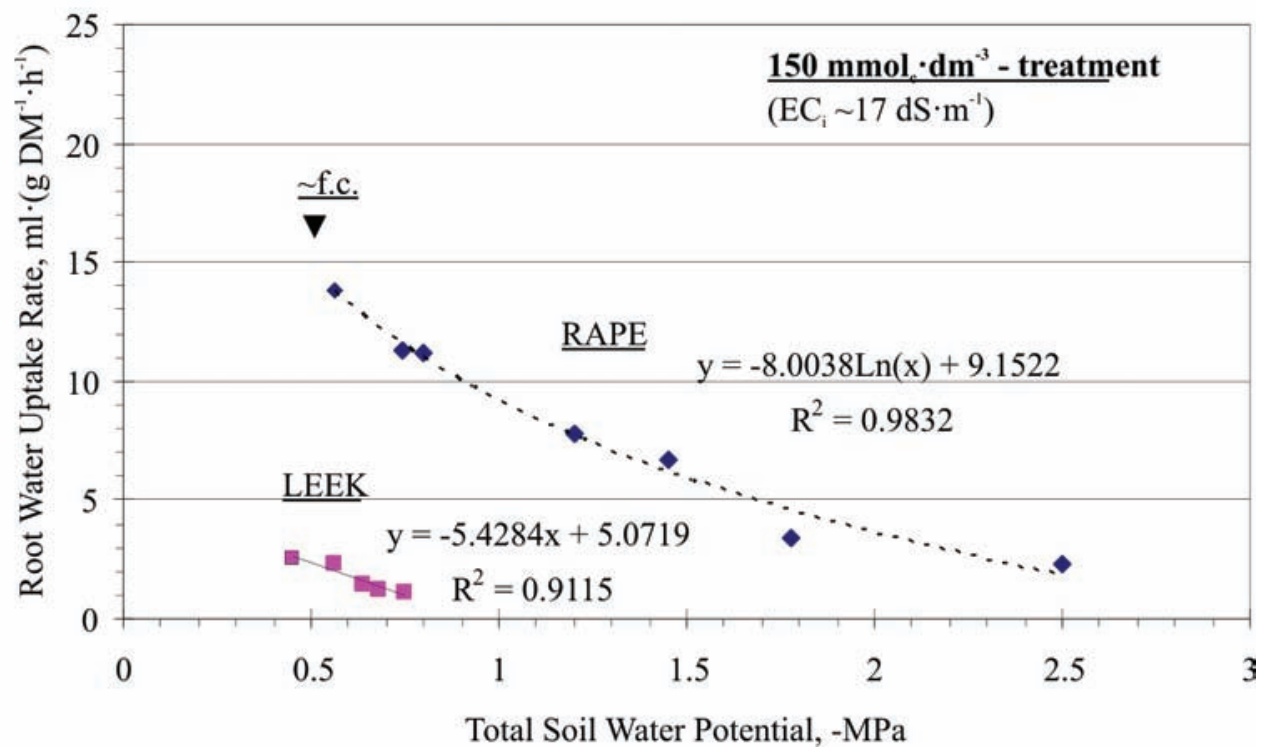

Figure 3. Root water uptake by leek and rape plants related from a moderately saline soil

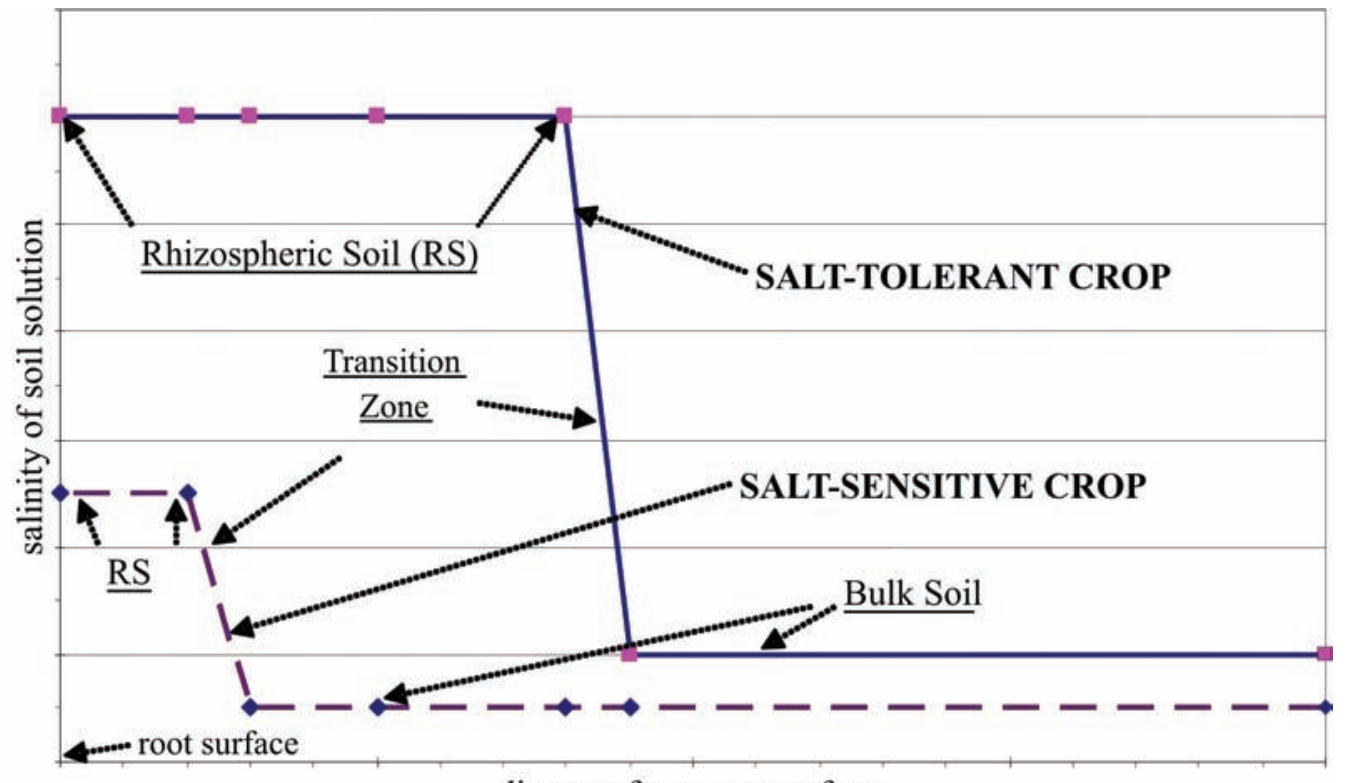

distance from root surface

Figure 4. Schematic presentation of lateral salt distribution around roots

\section{Research methods}

Leek and rape plants were pre-cultivated under well-controlled conditions in pots filled with a silty soil and then the soil was salinized with water containing $150 \mathrm{mmol} \cdot \mathrm{dm}^{-3}$ $\mathrm{NaCl}$, after which water uptake by the roots was determined bi-hourly.

\section{Results and discussion}

Water uptake by rape roots from saline soil solution was nearly $500 \%$ higher water uptake by leek roots (Fig. 3). I assume morphologic traits contribute to salt tolerance of irrigated crops. As shown in Figure 4, the formation of larger rhizospheric soil volumes improves salt tolerance, while a smaller soil volume enhances salt sensitivity. 


\section{References}

Riley D. \&. Barber S. A., 1970, Salt accumulation at the soybean (Glycin max. L.Merr.) root-soil interface, Soil Sci. Soc. Amer. Proc. 34: 154-155.

Schleiff U., 1987, A vegetation technique to study the water uptake by roots from salinized rhizospheric soils.
Zeitschrift fuer Pflanzenernaehrung und Bodenkunde 150: 139-146.

Schleiff U., 2010, The forgotten link in improving crop salt tolerance research under brackish irrigation: lateral soil salinity gradients around roots, [in:] M. Pessarakli (ed.), Handbook of Plant and Crop Stress, third edition, Taylor \& Francis Group, chapter 45: 1147-1154. 